\title{
O curso de serviço social da Unespar/Campus Apucarana: um estudo do perfil de seus egressos
}

\author{
The course social work Unespar / Campus Apucarana: a study of the profile of their \\ graduates
}

\author{
Júlio César Martins* \\ Luciane F. Zorzetti Maroneze** \\ Valdir Anhucci***
}

\begin{abstract}
Resumo
O objetivo deste artigo é apresentar o perfil dos egressos do curso de Serviço Social da Unespar/Campus Apucarana graduados no período de 2005 a 2017, considerando aspectos socioeconômicos, formação acadêmica, condições do exercício profissional e de trabalho, além de refletir sobre o perfil de profissional que o curso se propõe a formar. A proposta metodológica está baseada em uma abordagem qualitativa de caráter exploratório, utilizando a pesquisa de campo através do envio de questionário eletrônico. Considerando que a universidade não dispõe de um banco de dados sobre os egressos, acredita-se que o levantamento dos dados possa contribuir para discussões no curso de Serviço Social. Ademais, o artigo atenta para a necessidade da criação de um portal do egresso no site instituicional.
\end{abstract}

Palavras-chave: Serviço social. Formação acadêmico-profissional. Perfil do egresso.

\begin{abstract}
The objective of this article is to present the profile of the graduates of the Social Service course at Unespar / Campus Apucarana graduated in the period from 2005 to 2017, considering socioeconomic aspects, academic training, professional and work conditions, in addition to reflecting on the profile of professional that the course proposes to train. The methodological proposal is based on a qualitative approach of an exploratory nature, using field research through the sending of an electronic questionnaire. Considering that the university does not have a database of graduates, it is believed that the data collection can contribute to discussions in the Social Work course. Furthermore, the article highlights the need to create an egress portal on the institutional website.
\end{abstract}

Keywords: Social work. Academic-professional formation. Egress profile.

\footnotetext{
* Bacharel em Serviço Social e em Ciências Econômicas pela Universidade Estadual do Paraná UNESPAR/Campus Apucarana. Mestrando do Programa de Pós-graduação em Serviço Social e Política Social da Universidade Estadual de Londrina-UEL

** Assistente social, professora do curso de Serviço Social da Universidade Estadual do Paraná UNESPAR/Campus Apucarana. Doutoranda do Programa de Pós-graduação da Universidade Estadual de Londrina-UEL.

*** Professor do curso de Serviço Social da Universidade Estadual do Paraná UNESPAR/Campus Apucarana. Doutor pelo Programa de Pós-graduação da Universidade Estadual de Londrina-UEL.
} 
Introdução

A reflexão principal a que este artigo se propõe é apresentar o perfil dos egressos do curso de Serviço Social da Unespar/Campus Apucarana graduados no período de 2005 a 2017, considerando aspectos socioeconômicos, formação acadêmica, condições do exercício profissional e as condições de trabalho, além de refletir sobre o perfil de profissional que o curso se propõe a formar. Este artigo é fruto de uma pesquisa realizada para conclusão de curso efetuada em 2018.

As condições objetivas que um curso oferece podem impactar no processo de formação profissional, tais como: a execução da matriz curricular, programas das disciplinas, sistematização de ementas e conteúdos, efetivação do projeto pedagógico, falta de recursos financeiros para aquisição de livros, rotatividade de professores não concursados, entre outros. Desta forma, conhecer o curso de Serviço Social e suas particularidades, bem como o contexto e as condições da formação profissional dos sujeitos participantes da pesquisa foi fundamental.

É necessário destacar que o referido estudo é pioneiro no curso de Serviço Social da Unespar/Campus Apucarana, considerando que em quase duas décadas de existência não há registros de coleta de dados que abrangesse todos os bacharéis em Serviço Social. Ademais, a universidade não possui um banco de dados sistematizado que permita conhecer o perfil dos egressos que concluíram o curso na instituição.

O percurso metodológico baseia-se em uma abordagem qualitativa, de caráter exploratório. Assim, para atender ao objetivo do estudo fez-se necessária a elaboração de um instrumento de coleta de dados, realizada por meio de um formulário eletrônico online (Google Docs), o qual foi enviado a 389 (trezentos e oitenta e nove) egressos, dos quais 121 (cento e vinte e um) participaram da pesquisa, sendo que, 115 (cento e quinze) responderam ao questionário e 6 (seis) não desejaram participar da pesquisa. Os detalhes metodológicos estão descritos no decorrer deste artigo.

A pesquisa possibilitou identificar aspectos gerais do curso, bem como o levantamento do perfil dos egressos no que tange aos dados de identificação, formação, exercício profissional e condições de trabalho. A partir destes dados, espera-se contribuir para outros estudos e indicar a proposta de construção de uma base de dados que possa abranger os cursos ofertados pela universidade. 


\section{O Curso de Serviço Social na Unespar/Campus Apucarana}

A Universidade Estadual do Paraná (UNESPAR) ${ }^{1}$ é uma instituição de ensino superior pública e gratuita do Estado do Paraná, com sede no município de Paranavaí. Foi criada pela Lei Estadual no 13.283, de 25 de outubro de 2001 e alterada pela Lei Estadual no 17.590, de 12 de junho de 2013. Abrange uma área de 150 municípios, alcançando 4,5 milhões de pessoas. O quadro de servidores é composto por 1.077 pessoas que atendem mais de 12 mil alunos em cursos de graduação e pós-graduação (UNESPAR, [2018]).

A Unespar oferta 68 cursos de graduação, bacharelados e licenciaturas, distribuídos em seus sete campi e em 15 centros de áreas. Possui 10 programas próprios de pósgraduação stricto sensu (mestrado) em funcionamento e oferece ainda 19 cursos de especialização em diversas áreas do conhecimento (UNESPAR, [2018]).

Antes de ser incorporada a Unespar em 2001, a Faculdade Estadual de Ciências Econômicas de Apucarana (FECEA, [2018]) $)^{2}$ era composta por cursos vinculados exclusivamente a área de ciências sociais aplicadas, tais como: Ciências Econômicas, Ciências Contábeis, Administração, entre outros. Estes cursos marcaram tradicionalmente a história da faculdade, uma vez que a própria instituição de ensino tinha como objetivo central a formação de profissionais ligados a essas áreas do conhecimento.

Após a incorporação da FECEA à Unespar outros cursos passaram a ser ofertados além de Administração, Ciências Econônomicas, Ciências Contábeis, Serviço Social, Secretariado Executivo Trilíngue, Turismo, tais como: Pedagogia, Matemática, Letras Inglês, Letras Português, Letras Espanhol e Ciência da Computação, totalizando 12 cursos de graduação, divididos em dois centros de área: Centro de Ciências Sociais Aplicadas e Centro de Ciências Humanas e da Educação.

O curso de Serviço Social da Unespar/Campus Apucarana é ofertado desde 2002, tendo sido instituído pelo Decreto de Reconhecimento no 5.839 de 03 de julho de 2002, com

\footnotetext{
${ }^{1}$ Constitui-se em uma das sete universidades estaduais públicas do Paraná, abrangendo os seguintes campi: Apucarana, Campo Mourão, Curitiba I, Curitiba II, Paranaguá, Paranavaí, União da Vitória e a Escola Superior de Segurança Pública da Academia Policial Militar de Guatupê, unidade especial, vinculada academicamente à UNESPAR, por força do Decreto Estadual 9.538, de 05 de Dezembro de 2013 (UNESPAR, [2018]).

2 Através do Decreto no 26.298, sancionado no dia 17 de novembro de 1959, foi instituída juridicamente a Faculdade Estadual de Ciências Econômicas de Apucarana. No dia 20 de setembro de 1960 realizou-se a sessão solene de instalação da Faculdade Estadual de Ciências Econômicas de Apucarana-FECEA (UNESPAR, [2018]).
} 
O curso de serviço social da Unespar/Campus Apucarana: um estudo do perfil de seus egressos

fundamento no Parecer no 463/01, de 09 de novembro de 2001 da Câmara de Educação Superior, do Conselho Estadual de Educação (UNESPAR, [2018]). No ano de 2006 ocorreu o reconhecimento do curso através do Decreto n 6.102 publicado no Diário Oficial da União em 07 de fevereiro de 2006 (UNESPAR, [2018]). No ano de 2005, a então FECEA, formou sua primeira turma de Serviço Social.

A duração do curso de Serviço Social é de quatro anos com o cumprimento de uma carga horária de 3.000 horas/aulas, realizadas no período noturno com aulas presenciais e disciplinas anuais. São ofertadas 50 vagas por ano. Metade das vagas é disponibilizada para seleção através de vestibular e outra parte por meio do Sistema de Seleção Unificado (SISU) através da Resolução no 09/2015³. Em 2017 através do Decreto Estadual no 8.128 o curso passou por uma renovação de credenciamento pelo prazo de quatro anos. Ao longo de sua história, o curso já realizou alterações em seu Projeto Político Pedagógico nos anos 2006, 2009 e 2011, e desde 2016 passa por um processo de revisão do referido documento.

O corpo docente do curso de Serviço Social é constituído de 4 (três) professores doutores e 2 (três) professores mestres em processo de capacitação para obtenção de título de doutorado, todos efetivos e em Regime de Tempo Integral e Dedicação Exclusiva-TIDE ${ }^{4}$. Cabe destacar que todos os professores efetivos em regime de TIDE desenvolvem projetos de pesquisa e/ou extensão atualmente. O curso ainda dispõe de 1 (um) professor mestre temporário em regime de 40 horas; 1 (um) professor doutor temporário em regime de 20 horas; 2 (dois) professores mestres temporários em regime de 20 horas cada; além de contar com professores de outros centros de área de disciplinas não específicas do curso.

Atualmente a matriz curricular do curso de Serviço Social da Unespar/Campus Apucarana, contempla as seguintes disciplinas destacadas no Quadro 1 abaixo:

\footnotetext{
${ }^{3}$ Art. $1^{\circ}$ : Fica aprovada a adesão da Universidade Estadual do Paraná - Unespar ao Sistema de Seleção Unificada - SISU, do Ministério da Educação, para o processo seletivo das vagas iniciais dos Cursos de Graduação da Instituição, no percentual de 50\% (cinquenta por cento) das vagas (UNESPAR, 2015, p. 1).

4"No exercício da atividade docente sob dedicação exclusiva, o docente fica proibido de exercer cumulativamente outro cargo, função ou atividade particular de caráter profissional ou público de qualquer natureza. É também de interesse do programa, dar incentivo à pesquisa e a extensão, qualificando o trabalho acadêmico e abrir espaço para a Instituição de Ensino Superior (IES), criar intercâmbio de pesquisa e extensão com outras IES e Universidades de caráter nacional e internacional. Os projetos de pesquisa e extensão desenvolvidos dentro e fora da IES devem prever a disseminação anual dos resultados, por meio de publicações de artigos ou comunicações científicas em seminários ou congressos." (UNESPAR, [2018]).
} 
Quadro 1 - Matriz Curricular em vigência do curso de Serviço Social da Unespar/Campus Apucarana

\begin{tabular}{|c|c|}
\hline 10 Período & $\begin{array}{l}\text { Ciência Política; Formação Sócio-histórica do Brasil; Filosofia; Sociologia; } \\
\text { Antropologia; Economia Política; Fundamentos Históricos, Teóricos e } \\
\text { Metodológicos do Serviço Social I; Metodologia do Trabalho Acadêmico } \\
\text { e Questão Social e Serviço Social no Brasil. }\end{array}$ \\
\hline 2ㅇ Período & $\begin{array}{l}\text { Ética Profissional; Fundamentos Históricos, Teóricos e Metodológicos do } \\
\text { Serviço Social II; Psicologia Social; Direito; Oficina de Formação } \\
\text { Profissional em Serviço Social I; Gestão Social I; Processo de Trabalho; } \\
\text { Política Social I e Planejamento Social. }\end{array}$ \\
\hline 3 Período & $\begin{array}{l}\text { Pesquisa em Serviço Social; Gestão Social II; Seminário de Orientação de } \\
\text { Estágio I; Oficina de Formação Profissional em Serviço Social II; } \\
\text { Movimentos Sociais; Libras; Estágio Supervisionado I; Política Social II; } \\
\text { Serviço Social na Contemporaneidade; Prática Profissional I e Seminários } \\
\text { Temáticos I. }\end{array}$ \\
\hline 4ㅇ Período & $\begin{array}{l}\text { Ensino em Supervisão de Estágio em Serviço Social; Estatística; Prática } \\
\text { Profissional II; Seguridade Social; Seminário de Orientação de Estágio II, } \\
\text { Seminário de Trabalho de Conclusão de Curso, Seminários Temáticos II, } \\
\text { Trabalho de Conclusão de Curso; Estágio Supervisionado II e Atividades } \\
\text { Acadêmicas Complementares. }\end{array}$ \\
\hline
\end{tabular}

Fonte: O próprio autor (2018)

Na Região do Vale do Ivaí ${ }^{5}$, o curso de Serviço Social além de ser ofertado pela Unespar/Campus Apucarana é também oferecido pela Universidade Estadual de Maringá UEM/Campus Ivaiporã, sendo os únicos na modalidade presencial inseridos em universidades públicas nesta região. É importante destacar que atualmente no Paraná existem 10 cursos de Serviço Social ${ }^{6}$ na modalidade presencial ofertados em 6 instituições de ensino superior (IES) públicas estaduais e 2 de ensino superior (IES) públicas federais.

\footnotetext{
${ }^{5} \mathrm{O}$ território Vale do Ivaí está localizado na sua maior parte no Terceiro Planalto e parte no Segundo Planalto Paranaense e abrange uma área de $7.385,05 \mathrm{~km}^{2}$, que corresponde a cerca de $3,7 \%$ do território estadual. É constituído por 25 municípios: Apucarana, Arapuã, Ariranha do Ivaí, Barbosa Ferraz, Bom Sucesso, Borrazópolis, Califórnia, Cambira, Corumbataí do Sul, Cruzmaltina, Faxinal, Godoy Moreira, Grandes Rios, Ivaiporã, Jandaia do Sul, Jardim Alegre, Kaloré, Lidianópolis, Lunardelli, Marumbi, Novo Itacolomi, Rio Bom, Rio Branco do Ivaí, Rosário do Ivaí e São João do Ivaí. Esse conjunto de municípios reúne 309.021 pessoas, representando $3 \%$ da população estadual (IPARDES, 2007, p. 11).

${ }^{6}$ Instituições de ensino superior pública que ofertam o curso de Serviço Social no Paraná: Universidade Estadual do Paraná (UNESPAR) Campus de Apucarana e Paranavaí; Universidade Estadual de Maringá (UEM); Universidade Estadual de Londrina (UEL); Universidade Estadual do Oeste do Paraná (UNIOESTE) Campus de Toledo e Francisco Beltrão; Universidade Estadual de Ponta Grossa (UEPG); Universidade Estadual do Centro Oeste (UNICENTRO); Universidade Federal do Paraná (UFPR) e Universidade Federal da Integração LatinoAmericana (UNILA).
} 
Um dos desafios que se faz presente no curso da Unespar/Campus Apucarana é a inexistência de oferta pela instituição de curso stricto sensu e lato sensu em Serviço Social. O curso carece de uma discussão que promova a implantação de uma especialização stricto $e$ lato sensu, considerando a abrangência que o curso possui na Região do Vale do Ivaí, já que a continuidade dos estudos para o aprimoramento intelectual é um dos princípios fundamentais disposto no Código de Ética Profissional.

Outro desafio do curso que interfere na formação profissional refere-se à quantidade de professores temporários em relação ao número de efetivos. Desde o último concurso público realizado em 2010 na área de Serviço Social para o Campus de Apucarana o curso sofre com a falta de contratação de professores efetivos. Na tentativa de "sanar" essa falta, a abertura de processos seletivos tem se tornado frequente, pois essa modalidade tem como objetivo a contratação temporária de colaboradores para atividades exclusivas de ensino.

Outro aspecto importante que também deve ser considerado refere-se ao fato do curso ser noturno e parte dos estudantes serem trabalhadores. De acordo com Cardoso et al (1993) tem-se que observar as particularidades de um curso noturno, pois exige-se uma compreensão sobre o estudante trabalhador, já que é pouco o tempo dedicado a vida acadêmica.

Em uma pesquisa realizada em 2017 pelo curso para levantamento do perfil socioeconômico e cultural dos estudantes de Serviço Social da instituição, constatou-se que $52,4 \%$ dos estudantes exerciam atividade remunerada, dificultando assim a participação em atividades que iam além do ensino. Na mesma pesquisa verificou-se que $83,1 \%$ dos estudantes não frequentavam a universidade além do período de aula, levando a crer que a maioria dos estudantes não participava de atividades ligadas à pesquisa e extensão.

Essa realidade do curso de Serviço Social apresentada expressa em grande parte os ataques vinculados a uma política de ajuste neoliberal mais ampla. O cenário adverso de sucateamento do ensino superior público em âmbito nacional tem se adensado nas últimas décadas, interferindo diretamente no processo de formação dos estudantes, tendo em vista que os reflexos dessas ações implementadas pelos governos dificilmente serão compensadas.

Essas ações partem de um projeto instaurado de sucateamento e enfraquecimento do ensino superior autonônomo, público, gratuito e de qualidade. Destaca-se que o 
desmonte da política educacional no Brasil, embora, na atualidade tenha se acirrado, não é um processo recente, mas, data da introdução das ideias neoliberais adotadas no Brasil, a partir da década de 1990.

Após apresentar alguns desafios e particularidades do curso de Serviço Social da Unespar/Campus Apucarana, a pesquisa procurou identificar também o perfil profissional que este curso se propõe a formar. Portanto, buscou-se no projeto pedagógico do curso compreender o que se espera da formação profissional. O perfil do egresso que o curso se propõe é de um profissional que seja:

[...] generalista em sua formação intelectual e cultural munido de um acervo de informações, capaz de apresentar propostas inovadoras e criativas em seu campo de trabalho; [...] com capacidade para promover o exercício da cidadania e a participação dos usuários do Serviço Social na definição, formulação e controle das políticas sociais; [...] capaz de elaborar, executar e avaliar planos, programas e projetos na área social, assim como capaz de administrar benefícios e serviços sociais, prestar assessoria e consultoria a órgãos da administração pública e privada, e aos movimentos sociais; [...] um profissional imbuído da atitude investigativa, capaz de proceder a uma leitura crítica da realidade social sobre a qual atua (FECEA, 2009, p. 5).

Denota-se que o perfil profissional que o curso deseja formar está baseado nas Diretrizes Curriculares propostas pela Associação Brasileira de Ensino e Pesquisa em Serviço Socia (ABEPSS) em 1996, em consonância com a Lei de Regulamentação da Profissão no 8.662/1993. As Diretrizes Curriculares para os cursos de Serviço Social propostas pela Comissão de Especialistas de Ensino em Serviço Social, enfatiza o seguinte perfil profissional

[...] que atua nas expressões da questão social, formulando e implementando propostas para seu enfrentamento, por meio de políticas sociais públicas, empresariais, de organizações da sociedade civil e movimentos sociais. Profissional dotado de formação intelectual e cultural generalista crítica, competente em sua área de desempenho, com capacidade de inserção criativa e propositiva, no conjunto das relações sociais e no mercado de trabalho. Profissional comprometido com os valores e princípios norteadores do Código de Ética do Assistente Social (ABEPSS, 1996, p. 1).

Este perfil esperado é de um profissional com capacidade analítica e reflexiva para enfrentar as demandas postas na atuação profissional, além do mais, que seja capaz de realizar uma leitura crítica da realidade, aliando o conhecimento teórico e a prática profissional de forma orgânica e não dissociadamente.

É fundamental que o profissional estabeleça mediações, pois compreender o conhecimento teórico-prático de forma orgânica é estabelecer as mediações e não 
instrumentalizar o saber. Este perfil desejado deve ser propiciado por uma formação profissional que "[...] deve viabilizar uma capacitação teórico-metodológica e ético-política, como requisito fundamental para o exercício de atividades técnico-operativas, com vistas à apreensão crítica dos processos sociais numa perspectiva de totalidade" (ABEPSS, 1996, p.01).

A formação deve contribuir para o desenvolvimento de competências e habilidades específicas, conforme a Lei de Regulamentação da Profissão que dispõe sobre a profissão de assistente social, tais como: elaborar, executar, orientar, avaliar, realizar, planejar, organizar, administrar, entre outras habilidades, na área do Serviço Social (BRASIL, 1993), com objetivo de possibilitar a qualificação na construção de respostas profissionais, não obstante, isso envolve acesso à informação e a defesa de direitos dos usuários no enfrentamento às expressões da questão social, tão latentes na atualidade, que:

[...] não é senão as expressões do processo de formação e desenvolvimento da classe operária e de seu ingresso no cenário político da sociedade, exigindo seu reconhecimento como classe por parte do empresariado e do Estado. É a manifestação, no cotidiano da vida social, da contradição entre o proletariado e a burguesia [...] (IAMAMOTO, 2005. p. 77).

É preciso destacar também que os dados coletados possuem relevância para subsidiar a discussão do Projeto Pedagógico do Curso, visto que evidenciam elementos importantes para pensar o processo de formação profissional.

Um projeto pedagógico não deve ser apenas uma formalidade, um mero documento, mas sim um processo no qual participem os sujeitos envolvidos na formação profissional, visto que expressa aquilo que se espera do curso. Silva (1998) sinaliza que historicamente no Brasil, os projetos representam apenas declarações, marcados pela ideia de controle e influência tecnicista, significando mais uma padronização nacional, nos quais predomina uma visão de racionalidade técnica.

A autora aponta que os projetos pedagógicos precisam ser compreendidos e efetivados enquanto construções coletivas que ofereçam sentido a todos os envolvidos, pois um projeto pedagógico é um projeto de formação profissional, portanto deve conter qualidade e concreticidade. Daí também a importância deste processo ser realizado coletivamente e de incorporar elementos que possam traduzir potenciais redefinições, a exemplo do que pensam os egressos, para além do corpo docente e discente. Assim, um 
projeto pedagógico não é estático, além da importância de sua existência, a sua manutenção e reflexão se fazem necessárias.

Silva (1998) destaca a dimensão política do projeto pedagógico, ressaltando que este representa, para além do planejamento de um curso, um projeto de sociedade, de cidadãos que pretende formar e quais os compromissos que estes terão com a sociedade que se espera construir. Sinaliza-se, ainda, que não podem ser estruturas fragmentadas da formação, isoladas no âmbito da estrutura universitária, mas concebidos por todos para desenvolver identidades, ou seja, é preciso avançar no significado de um projeto, para além de se traduzirem apenas em conjuntos de disciplinas e conteúdos.

Em suma, um projeto deve fazer sentido para os estudantes, professores, egressos e demais envolvidos. Neste sentido, Portes $(2016$, p. 114) ao discutir sobre o projeto pedagógico observa que embora esse documento "[...] expresse a direção, os princípios e as diretrizes da formação profissional, não é uma proposta isolada e totalmente autônoma".

A partir da pesquisa, foi possível aproximar-se das particularidades e características do curso, mesmo diante de uma conjuntura de ataques ao ensino superior que vem se intensificando nas últimas décadas em nosso país. Nos próximos itens serão explicitados os procedimentos metodológicos adotados na pesquisa, bem como os dados coletados e os resultados obtidos.

\section{O Caminho Metodológico da Pesquisa}

Como parte do objetivo geral deste trabalho, buscou-se coletar informações acerca do perfil dos egressos do curso de Serviço Social da Unespar/Campus Apucarana, em diversos aspectos, tais como: socioeconômico, formação acadêmica, condições do exercício profissional e as condições de trabalho.

Desta forma, delimitou-se como universo da pesquisa, os egressos do curso de Serviço Social da Unespar/Campus Apucarana, que se graduaram na instituição entre os anos de 2005 (1a turma de formandos) e 2017 (última turma de formandos até dezembro/2018), compreendendo, portanto, todas as turmas graduadas pelo curso. 0 envio de questionários por ano de conclusão de curso se deu conforme o Quadro 2 abaixo:

Quadro 2 - Quantidade de envio de questionários por ano de conclusão de curso 
O curso de serviço social da Unespar/Campus Apucarana: um estudo do perfil de seus egressos

\begin{tabular}{|c|c|c|c|c|}
\hline $\begin{array}{c}\text { Ano de } \\
\text { Conclusão de } \\
\text { Curso }\end{array}$ & $\begin{array}{l}\text { Quantidade de } \\
\text { Questionários } \\
\text { enviados por } \\
\text { turma }\end{array}$ & $\begin{array}{l}\text { Quantidade de } \\
\text { Questionários } \\
\text { NÃO enviados }\end{array}$ & $\begin{array}{c}\text { Quantidade de } \\
\text { questionários } \\
\text { respondidos }\end{array}$ & $\begin{array}{c}\text { Total de } \\
\text { Formandos }\end{array}$ \\
\hline 2005 & 25 & 5 & 10 & 30 \\
\hline 2006 & 25 & 3 & 2 & 28 \\
\hline 2007 & 32 & 8 & 9 & 40 \\
\hline 2008 & 41 & 4 & 17 & 45 \\
\hline 2009 & 27 & 5 & 7 & 32 \\
\hline 2010 & 32 & 6 & 10 & 38 \\
\hline 2011 & 30 & 2 & 10 & 32 \\
\hline 2012 & 34 & 2 & 9 & 36 \\
\hline 2013 & 24 & 5 & 5 & 29 \\
\hline 2014 & 37 & 3 & 9 & 40 \\
\hline 2015 & 25 & 1 & 4 & 26 \\
\hline 2016 & 20 & 1 & 4 & 21 \\
\hline 2017 & 37 & 0 & 19 & 37 \\
\hline TOTAL & $\begin{array}{c}389 \\
(89,63 \%)\end{array}$ & $\begin{array}{c}45 \\
(10,37 \%)\end{array}$ & $\begin{array}{c}115 \\
(29,56 \%)\end{array}$ & $\begin{array}{c}434 \\
(100 \%)\end{array}$ \\
\hline
\end{tabular}

Fonte: O próprio autor (2018)

A listagem dos concluintes com os respectivos e-mails foi fornecida pela secretaria acadêmica. A partir da listagem fornecida foi realizada a conferência com a ata da solenidade de colação de grau, totalizando 434 bacharéis em Serviço Social, entre os anos de 2005 e 2017, compondo assim o universo de pesquisa deste trabalho somente os que concluíram o curso.

\footnotetext{
${ }^{7}$ Não foi possível encaminhar o questionário, pois os estudantes não possuíam e-mails cadastrados na base de dados da instituição.
} 
Com o intuito de obter as respostas dos egressos com maior celeridade e considerando a disponibilidade dos e-mails fornecidos pela instituição de ensino, optou-se por elaborar um questionário eletrônico, utilizando a plataforma de aplicativos online Google Docs. O questionário foi dividido em cinco blocos de questões. O primeiro bloco refere-se ao "Termo de Consentimento Livre e Esclarecido" contendo o objetivo da pesquisa, bem como informações aos respondentes sobre autorização para análise de dados e sigilo das informações obtidas.

O segundo bloco buscou coletar informações referentes aos dados gerais dos egressos, tais como: nome, idade, sexo, orientação sexual, identidade racial, estado civil, religião, filiação partidária, participação em movimentos sociais, em organização sindical e da categoria e o município e unidade da federação em que residem atualmente.

O terceiro bloco consistiu na coleta de dados referentes à formação acadêmica. Neste bloco os egressos responderam questões sobre: ano de conclusão do curso, modalidade do curso (presencial ou à distância), em quantos anos a graduação foi concluída, nível de especialização atual e, por fim, se possuia graduação em outro curso.

O quarto bloco buscou coletar dados acerca do exercício profissional, a partir das seguintes questões: se o egresso exercia a profissão de assistente social, qual o município de atuação profissional, em que área atuava ou atuou em seu último vínculo, quanto tempo demorou a atuar profissionalmente, há quanto tempo atuava como assistente social e há quanto tempo estava no atual vínculo empregatício. No último bloco buscou-se coletar os dados em relação às condições de trabalho do profissional. Este bloco abrangeu questões como: atual tipo de vínculo empregatício, tipo de contrato que o profissional possuía no atual emprego, carga horária de trabalho, média salarial, existência de plano de carreira no atual emprego e a função que exercia.

A partir do envio dos 389 questionários, houve o retorno de 121, o que corresponde a 31,10\% dos questionários enviados. Destes, 115 questionários $(95,04 \%)$ foram respondidos e $6(4,96 \%)$ não aceitaram participar da pesquisa. Desta forma, o perfil do egresso que será apresentado a seguir é composto pelas respostas dos egressos que participaram da pesquisa. Obteve-se o retorno de egressos de todas as turmas do período analisado, conforme disposto no Quadro 2.

Diante dos dados preliminarmente apresentados, observa-se que houve um considerável retorno de questionários respondidos. Considerando o universo de pesquisa, as respostas representam aproximadamente 30\% de todos os egressos formados de 2005 a 
2017. No item a seguir será apresentado o perfil do egresso do curso de Serviço Social da Unespar/Campus Apucarana.

\section{O Perfil dos Egressos}

Compreende-se que construir um perfil é ir muito além da apresentação dos dados tabulados, é buscar compreender ao longo de quase duas décadas de existência do curso as relações e mediações estabelecidas com a realidade e suas determinações sociais, ou seja, o estudo não buscou apenas descrever os dados, mas analisá-los a partir de uma dada

conjuntura. É preciso ter claro que este trabalho não se propõe unicamente a expor as condições que o curso de Serviço Social da Unespar/Campus Apucarana se encontra, mas também enquanto um instrumento de amostra, apresentando dados que possam demonstrar o perfil do egresso em vários aspectos.

A partir dos dados coletados, verificou-se que a maioria dos egressos é do sexo feminino, sendo 101 mulheres e 14 homens, o que expressa uma tendência histórica da profissão. Um levantamento realizado em 2005 pelo Conselho Federal de Serviço Social (CFESS) em parceria com a Universidade Federal de Alagoas (UFAL) e os Conselhos Regionais de Serviço Social (CRESS), também apontou essa tendência em nível nacional.

Em relação à idade, 39\% possuiam entre 31 e 40 anos, 37\% entre 26 e 30 anos, 17\% entre 20 e 25 anos, 4\% entre 41 e 50 anos, 3\% entre 51 e 60 anos e apenas $1 \%$ afirmou ter acima de 60 anos. Quando questionados sobre a orientação sexual, 92\% dos egressos afirmaram serem heterossexuais, $4 \%$ homossexuais e $4 \%$ bissexuais.

Em relação à religão, a católica se apresenta majoritariamente com $55 \%$, seguidos por protestantes: $22 \%$, não possui religião: $17 \%$, espíritas: $3 \%$ e adeptos de outras religiões: $3 \%$. Sobre a identidade racial, a maioria se declarou branco: $71 \%$, seguido por pardos: $18 \%$, pretos: $9 \%$, amarelos: $1 \%$ e indígenas: $1 \%$. Por fim, $46 \%$ são casados, $40 \%$ solteiros, $6 \%$ divorciados e $8 \%$ afirmaram estar em uma união estável.

A pesquisa também buscou identificar dados com relação à participação dos egressos em partidos políticos, movimentos sociais, organizações sindicais e órgãos representativos da categoria profissional, reconhecendo desta forma, a relevância desses espaços na organização de lutas coletivas. É importante destacar que não se pode considerar partido político, sindicato e movimentos sociais como sendo todos iguais e com o mesmo 
propósito. Ao delimitar esses espaços, buscou-se reconhecê-los como espaços de participação coletiva, com particularidades no que se refere aos objetivos políticos e ideológicos.

Os dados demonstram que é baixo o número de egressos que estão inseridos nestes espaços, sendo que apenas $9 \%$ são filiados a partidos políticos, $12 \%$ participam de movimentos sociais, $17 \%$ em organização sindical e $21 \%$ participam de órgãos representativos da categoria profissional. Diante dos dados coletados fica evidenciado que a porcentagem de não vinculação dos egressos a esses espaços ultrapassa 75\%, o que se configura como um dado expressivo. Porém, este é um dado também observado em um contexto maior, conforme a pesquisa realizada pelo CFESS/CRESS.

Atualmente, é possível observar uma redução de participação e também uma diminuição dos sindicatos, dada a conjuntura política, econômica e social marcada pela força das políticas neoliberais, as quais também possuem um poder ideológico, dificultando as decisões coletivas, pregando o individualismo e as decisões verticais. Isso faz compreender que a participação não está desvinculada das bases materiais que determinam as relações sociais de produção. Neste sentido, Gohn (2008), analisando o neoliberalismo e seus reflexos na participação social, aponta que:

O papel do Estado na oferta dos serviços públicos foi flexibilizado ou desregulamentado, ficando o mesmo como gestor e controlador dos recursos, transferindo a responsabilidade para organizações da sociedade civil organizada, via programas de parcerias em projetos e programas sociais com as ONGs. Com isso, os sindicatos enfraqueceram - lutar pela não demissão, pelo emprego em si, tornou-se mais importante que lutar por melhores salários [...] o número de manifestações nas ruas diminuiu e inverteu-se a relação, as ONGs tomaram a dianteira na organização da população, no lugar dos movimentos (GOHN, 2008, p. 108).

É preciso considerar que os assistentes sociais, enquanto classe trabalhadora, também estão imersos nesta conjuntura e, além disso, encontram dificuldades objetivas e subjetivas para a participação em tais espaços. Porém, o Código de Ética da profissão estabelece enquanto direito do assistente social "[...] apoiar e/ou participar dos movimentos sociais e organizações populares vinculados à luta pela consolidação e ampliação da democracia e dos direitos de cidadania" (CFESS, 1993, p.34), configurando desta forma, esses espaços enquanto lócus privilegiado de decisões coletivas.

Os dados apresentados evidenciam que a participação ainda é um desafio. A fim de exemplificar tal problemática, em alguns eventos do Núcleo do Conselho Regional de Serviço 
Social de Apucarana (NUCRESS-Apucarana) que o pesquisador pôde participar foi relatado pela coordenação a dificuldade de reorganização do órgão representativo da categoria no Vale do Ivaí. Outro espaço importante de participação que também relatou dificuldades de articulação dos profissionais é o Fórum de Supervisão de Estágio ofertado pelo curso aos supervisores de campo, que segundo a coordenadora do fórum a participação ainda é muito baixa, seja por impossibilidade de liberação dos empregadores, seja pelo grande fluxo de trabalho dos supervisores que acaba dificultando a participação.

A partir dessa problemática, os apontamentos e as discussões assinalam que a participação é um elemento fundamental para o processo de luta e conquista de direitos e, portanto, dado o caráter da profissão, é extremamente relevante que o assistente social esteja inserido em tais espaços, que haja uma maior vinculação com os movimentos sociais, sindicais, enquanto possibilidade de refletir e problematizar ações coletivamente, numa perspectiva crítica e anticapitalista.

Os dados coletados também apontam que todos os egressos que responderam ao questionário iniciaram e concluíram o curso nessa universidade. Dos egressos que responderam $65 \%$ possuem curso de especialização, todavia, não questionou se de maneira presencial ou à distância, o que denota que a maioria teve possibilidade de continuar os estudos.

Apenas $4 \%$ dos egressos possuem cursos de pós-graduação na modalidade stricto sensu. Este dado é salutar para o curso, visto que a formação profissional também precisa oferecer condições para ingresso na pós-graduação. Expressa, ainda, as condições de acesso aos programas de pós-graduação stricto sensu em Serviço Social, sendo que o mais próximo, na região, é ofertado pela Universidade Estadual de Londrina (UEL).

Dos 115 egressos que responderam ao questionário, 23 afirmaram possuir uma segunda graduação, porém não se sabe se anterior ou posteriormente a ter cursado Serviço Social. Dentre as graduações informadas destaca-se o curso de Pedagogia e Direito.

Na sequência, buscou-se estreitar a coleta de dados apenas aos egressos que estavam exercendo a profissão ou que já haviam atuado como assistentes sociais. Nesse sentido, 70 (61\%) dos 115 egressos respondentes estavam atuando como assistentes sociais e $15(13 \%)$ já exerceram a profissão em algum momento após a conclusão do curso. 0 restante dos egressos respondentes, que totaliza $30(26 \%)$ informaram que nunca atuaram profissionalmente após a conclusão do curso. 
Isto posto, a apresentação dos dados a seguir, refere-se exclusivamente aos egressos que estavam atuando ou que já atuaram como assistentes sociais já que o 4o bloco de questões tinha relação com a atuação profissional. Portanto, a amostra da coleta de dados passa a ser 85 respondentes, representando $74 \%$ dos egressos que responderam ao questionário.

Em relação aos municípios nos quais os egressos atuavam, verificou-se que a maior parte permanece trabalhando em municípios próximos a Apucarana, totalizando aproximadamente $50 \%$ (40) dos egressos. Diante deste dado observa-se que a instituição cumpre um papel científico e social para a comunidade localizada próxima a sua área de abrangência, sobretudo a Região do Vale do Ivaí, na qual se concentra a maior parte de profissionais que estão atuando.

Cabe destacar, ainda, que além dos municípios que ficam próximos a Apucarana, outras cidades do estado do Paraná e também outros estados foram assinaladas como munícipio de atuação profissional, tais como: Terra Roxa (1), São José dos Pinhais (1), Paraná (1), Curitiba (1), Cerro Azul (1), Carlópolis (1), não responderam (2), Foz do Iguaçu (2) e outros estados (SP, RJ, PE) (6). O quadro 3, abaixo, apresenta o município de atuação profissional dos egressos que responderam ao questionário:

Quadro 3 - Municípios de atuação profissional dos egressos respondente

\begin{tabular}{|c|c|}
\hline Município & $\begin{array}{c}\text { Quantidade de } \\
\text { Profissionais }\end{array}$ \\
\hline Apucarana & 13 \\
\hline Arapongas & 10 \\
\hline Astorga & 3 \\
\hline Borrazópolis & 2 \\
\hline Califórnia & 3 \\
\hline Cambira & 1 \\
\hline Cornélio Procópio & 1 \\
\hline Cruzeiro do Sul & 1 \\
\hline Faxinal & 1 \\
\hline Grandes Rios & 2 \\
\hline Ivaiporã & 3 \\
\hline Jandaia do Sul & 3 \\
\hline Kaloré & 2 \\
\hline Londrina & 5 \\
\hline Mandaguari & 4 \\
\hline Marialva & 1 \\
\hline
\end{tabular}


O curso de serviço social da Unespar/Campus Apucarana: um estudo do perfil de seus egressos

\begin{tabular}{|c|c|c|}
\hline Maringá & 1 \\
\cline { 2 - 3 } & Mauá da Serra & 2 \\
\hline Rio Bom & 1 \\
\hline Rolândia & 1 \\
\hline São João do Ivaí & 1 \\
\hline São Pedro do Ivaí & 1 \\
\hline Sarandi & 2 \\
\hline Tamarana & 1 \\
\hline Telemâco Borba & 1 \\
\hline
\end{tabular}

Fonte: O próprio autor (2018)

Ao serem questionados em que área atuavam ou atuaram, $57 \%$ dos egressos citaram a assistência social como área de maior atuação profissional, seguidos por $12 \%$ atuando na área da saúde, $12 \%$ no terceiro setor, $11 \%$ na educação, $4 \%$ no judiciário, $2 \%$ outras áreas não especificadas e 1\% habitação e 1\% previdência social.

Historicamente, o Serviço Social esteve vinculado à política de saúde que compõe o tripé da Seguridade Social. A participação dos profissionais na VIII Conferência Nacional de Saúde, o Movimento de Reforma Sanitária, e a promulgação da Constituição Federal de 1988, representaram avanços na área da saúde, os quais possibilitaram a inserção dos assistentes sociais com a ampliação dos campos de trabalho, sobretudo com a implantação do Sistema único de Saúde (SUS).

Segundo Almeida e Alencar (2011), o assistente social é um dos profissionais reconhecidos legalmente como trabalhador da saúde. Isso lhe permite um reconhecimento institucional diante das funções e práticas exercidas nos serviços de saúde. Outro aspecto importante que confere legitimidade ao trabalho profissional nesta área refere-se à Resolução no 218/1997 formulada pelo Conselho Nacional de Saúde (CNS) e ratificada pelo CFESS por meio da Resolução no 383/1999, a qual considera o assistente social como um profissional da saúde.

A política de assistência social também se apresentou como espaço sócioocupacional de maior atuação dos egressos respondentes. De acordo com Raichelis (2010, p. 752)

Ainda que a política de assistência social seja um campo de trabalho multiprofissional e interdisciplinar, ela se constitui historicamente como uma das principais mediações do exercício profissional dos assistentes sociais, sendo reconhecidos socialmente (e se autorreconhecendo) como os profissionais de 
referência desta política, apesar das ambiguidades que cercam essa relação de longa data.

Diante do exposto fica evidenciado que a política de assistência social, além de se constituir como um campo de múltiplas possibilidades de atuação profissional é através dela que a própria profissão é reconhecida socialmente, tornando o assistente social referência nesta política. Ademais, historicamente o assistente social sempre esteve vinculado à assistência social como um de seus principais campos de atuação profissional.

$\mathrm{Na}$ última década houve um considerável aumento do campo de atuação do assistente social nesta política, principalmente com a implantação do Sistema Único de Assistência Social (SUAS), passando a ser a área que mais requisita profissionais do Serviço Social. Segundo Delgado (2013) esta expansão se deu, especialmente, após a Resolução no 269, de 13 de dezembro de 2006 que aprovou a Norma Operacional Básica de Recursos Humanos do SUAS (NOB-RH/Suas), determinando que os assistentes sociais passasse a fazer parte das equipes de referência.

Por fim, a terceira maior área de atuação dos egressos é a política de educação. Nas últimas décadas tem crescido significativamente a produção e reflexão acerca da atuação do Serviço Social nesta política, particularmente em escolas públicas ou em outras instâncias da política educacional pública. Os subsídios para atuação de assistentes sociais na política de educação dispõem que:

A educação pode ser considerada um espaço privilegiado para o enriquecimento ou empobrecimento do gênero humano. Assim, na perspectiva de fortalecimento do projeto ético-político, o trabalho do/a assistente social na Política de Educação pressupõe a referência a uma concepção de educação emancipadora, que possibilite aos indivíduos sociais o desenvolvimento de suas potencialidades e capacidades como gênero humano (CFESS, 2011, p. 33).

O assistente social na educação atua nas políticas de prevenção, observando no espaço escolar as manifestações das expressões da questão social, a partir de uma análise da realidade na qual o indivíduo está inserido. As competências e habilidades profissionais permitem realizar a análise crítica da realidade e construir as estratégias necessárias para responder às demandas sociais que estão estabelecidas na lei de regulamentação da profissão, por meio das competências e atribuições privativas do assistente social.

Através dos dados coletados, nota-se outra tendência histórica da profissão, isto é, a inserção do Serviço Social na esfera pública estatal. De acordo com os dados da pesquisa, 
$72 \%$ atuavam em algum órgão público, todavia, não questionou-se se na esfera municipal, estadual ou federal. De acordo com o CFESS (2005) esta também tem sido uma realidade nacional, demonstrando que "[...] o Estado tem sido historicamente o maior empregador dos assistentes sociais, atribuindo uma característica de servidor público a este profissional." (IAMAMOTO, 2009, p. 17).

Objetivando coletar informações acerca das condições de trabalho nos espaços sócio-ocupacionais, buscou-se verificar de que forma ocorreu a contratação do profissional pelo campo de atuação em que estava inserido. Os dados apontaram que $61 \%$ foram contratados através de concursos públicos, $14 \%$ por indicação de outrem, $11 \%$ por meio de processo seletivo, $6 \%$ cargo em comissão e $8 \%$ outras formas de contratação.

Ao serem questionados sobre a carga horária, os assistentes sociais afirmaram que $42 \%$ deles trabalhavam entre 30 e 40 horas semanais, $37 \%$ entre 20 e 30 horas semanais, $10 \%$ acima de 40 horas semanais, $8 \%$ entre 10 e 20 horas semanais e apenas $3 \%$ entre 5 e 10 horas semanais. Considerando a aprovação da Lei № 12.317, de 26 de agosto de 2010, que institui a duração da carga horária de 30 horas de trabalho para o assistente social, faz-se necessário destacar a luta histórica para aprovação de referida lei por parte da categoria profissional. De acordo com Boschetti (2011, p. 567),

A redução da jornada de trabalho para trinta horas semanais sem redução salarial, ainda que não altere estruturalmente a organização do trabalho, possibilita diminuir a sobrecarga do trabalho, o que pode melhorar a saúde do (a) trabalhador (a) e, ainda impor limites à exploração do trabalho pelo capital.

De acordo com a autora, é possível inferir que a conquista da categoria profissional pela redução da carga horária para 30 horas semanais, além de possibilitar melhores condições do exercício profissional, contribui para a diminuição do excesso de trabalho e a redução dos níveis de desgaste e estresse aos que os profissionais estão expostos.

Todavia, é preciso atentar-se para duas possíveis consequências provenientes da fixação da jornada de 30 horas de trabalho dos assistentes sociais. A primeira seria a criação de mais postos de trabalho, considerando a necessidade do empregador para tempo integral de trabalho, já a segunda consequência seria o pluriemprego, tendo em vista que a redução da jornada de trabalho possibilita vínculos empregatícios precários e com baixos salários, em virtude disso, o profissional se vê obrigado a aceitar uma dupla ou tripla jornada de trabalho para aumentar sua renda salarial (DELGADO, 2013). Entretanto, os assistentes sociais 
juntamente com o conjunto CFESS/CRESS encontram dificuldades para efetivação do cumprimento da legislação, "[...] como era de se esperar numa sociedade de classes, muitos empregadores ainda resistem a aplicá-la ou a aplicam de modo equivocado" (DELGADO, 2013, p. 139).

Os respondentes também foram consultados sobre a média salarial. Sobre esse dado, $48 \%$ dos respondentes recebem entre 1 e 3 salários mínimos, 38\% entre 3 e 6 salários mínimos, $12 \%$ entre 6 a 9 salários mínimos e apenas $2 \%$ até 1 salário mínimo. Objetivando estabelecer condições mínimas de remuneração para o exercício profissional, em 2005 o CFESS aprovou uma nova Resolução no 467, “[...] estabelecendo gradações no valor da hora técnica de acordo com o nível de formação pós-graduada do assistente social" (DELGADO, 2013, p. 144). Em relação à média salarial respondida pelos assistentes sociais egressos, cabe salientar que segundo Delgado (2013) o CFESS através da Resolução no 418/2001, instituiu a Tabela Referencial de Honorários do Serviço Social (TRHSS), objetivando estabelecer condições mínimas de remuneração para o exercício profissional.

Ao questionar a existência de plano de carreira, constatou-se que $62 \%$ das instituições empregadoras não dispõem de plano de carreira profissional e $38 \%$ ofertam essa possibilidade aos assistentes sociais empregados. Diante dos dados apresentados, denota-se que a implantação de um plano de carreira e salários por parte dos empregadores constituise em desafios para categoria profissional, uma vez que a efetivação de um plano implica em melhores condições de trabalho ao assistente social, e nem sempre interessa ao empregador garantir tais condições como: melhores salários, licenças remuneradas, possibilidade de ascensão profissional, licenças prêmios, gratificações por tempo de serviço, entre outros.

A contrarreforma trabalhista aprovada através Lei $n=13.467 / 2017$, que alterou a Consolidação das Leis do Trabalho (CLT) estabeleceu uma série de medidas e trouxe novas definições sobre férias, jornada de trabalho, adicionais, plano de salários, horas extras, trabalho intermitente, rescisão contratual, contribuição sindical, descanso entre outros, impactando diretamente na vida da classe trabalhadora. Denota-se que no bojo dessas contrarreformas em curso "[...] certamente ampliarão as desigualdades e a barbarização da vida social no Brasil e, consequentemente, tornarão mais difíceis às condições de resistência da classe trabalhadora" (CFESS, 2017, p. 02).

Buscou-se também coletar informações acerca da função que exerciam no atual emprego. Aproximadamente $75 \%$ dos respondentes afirmaram exercer a função de assistente social, $18 \%$ outras funções, $4 \%$ exercem o cargo de coordenador, $3 \%$ de diretor e 
$1 \%$ de chefe. Denota-se que embora haja $18 \%$ dos profissionais que exerçam outras funções que não de coordenador, chefe ou diretor, não se questionou que função seria. É importante destacar que estes dados obtidos em relação às condições de trabalho expressam uma realidade que tem sido problematizada pela categoria, inclusive pelo conjunto CFESS/CRESS.

Diante da coleta de dados, sinaliza-se a necessidade da Unespar/Campus Apucarana estabelecer canais de comunicação permanentes com os egressos, nesse sentido, sugere-se que seja criado um portal do egresso no próprio site da instituição. Este portal poderá possibilitar que os egressos permaneçam em contato com a universidade, possuindo acesso a informações, documentos, registros e dados importantes sobre a sua formação. Deste modo, o egresso manteria algum vínculo com a instituição de ensino e esta, por sua vez, contaria com um banco de dados sobre os ex-alunos, possibilitando, por exemplo, a construção deste perfil.

Entende-se a importância de um portal do egresso "[...] para além do tempo da formação profissional dando continuidade a uma história comum que começa no curso de graduação, mas não termina com a diplomação do aluno, segue com sua inserção profissional na sociedade e na educação ao longo da vida profissional" (UEL, [2018]). Desta forma, essa iniciativa pode assegurar um canal permanente de comunicação com ex-alunos, para que possam expressar suas opiniões e observações sobre o curso e a instituição de ensino, auxiliando assim num processo contínuo de melhoria.

\section{Resultados e Conclusões}

Considerando a quantidade de egressos que responderam ao questionário, que representa $29,56 \%$, ou seja, aproximadamente $1 / 3$ (um terço) do universo pesquisado, é possível estabelecer um perfil, ainda que este não represente a totalidade. Os dados coletados permitem concluir que a maioria dos egressos é composta por mulheres, de religião católica, heterossexuais, cor branca, com idade entre 26 e 40 anos.

A maioria não participa de organizações sindicais, movimentos sociais e órgãos representativos da categoria. A maior parte é graduada e especialista, exercendo profissão, atuando majoritariamente na política de assistência social. Com relação às condições de trabalho, a maioria foi contratada via concurso público e atua em órgãos públicos, com carga horária entre 30 e 40 horas, com remuneração entre 1 e 3 salários mínimos, exercendo 
cargo de assistente social, porém, a pesquisa constatou que a maioria não conta com planos de carreira em seu atual vínculo empregatício.

Ao chegar ao perfil do egresso a intenção era conhecer os sujeitos da pesquisa e também de oferecer para a universidade dados que possam contribuir para o aperfeiçoamento do curso e da própria instituição de ensino. A partir dos dados apresentados, sinalizou-se a importância da construção de um canal de comunicação entre a instituição e os egressos.

Outrossim, este trabalho teve como objetivo apresentar um perfil na perspectiva de conhecer os egressos do curso, e também de oferecer a universidade dados que possam contribuir para o aperfeiçoamento do curso e da própria universidade. Conhecer o curso e o egresso do curso de Serviço Social da Unespar/Campus Apucarana representou uma primeira aproximação para compreender as condições da formação e do exercício profissional, uma vez que este estudo requer uma pesquisa mais densa, considerando outras variáveis como os docentes, a instituição de ensino e não somente isso, implica também conhecer uma totalidade maior, qual seja, a própria educação pública superior.

Por fim, diante dos dados apresentados é possível afirmar que houve um considerável retorno de questionários respondidos que compuseram o banco de dados da pesquisa. Desta forma, as informações coletadas possuem significativa relevância, pois podem possibilitar discussões futuras no curso de Serviço Social da Unespar/Campus Apucarana.

\section{Referências}

ABEPSS - ASSOCIAÇÃO BRASILEIRA DE ENSINO E PESQUISA EM SERVIÇO SOCIAL. Diretrizes gerais para o curso de Serviço Social: com base no currículo mínimo aprovado em assembléia geral extraordinária de 8 de novembro de 1996. Rio de Janeiro: ABEPSS, 1996.

ALMEIDA, Ney Luiz Teixeira de; ALENCAR, Mônica Maria Torres de. Serviço Social: trabalho e políticas públicas. São Paulo: Saraiva, 2011. p. 119-171.

BOSCHETTI, Ivanete. Condições de trabalho e a luta dos(as) assistentes sociais pela jornada semanal de 30 horas. Serviço Social e Sociedade, São Paulo, n. 107, p. 557-584, jul/set. 2011.

BRASIL. Lei no 12.317, de 26 de agosto de 2010. Acrescenta dispositivo à Lei n. 8.662, de 7 de junho de 1993, para dispor sobre a duração do trabalho do assistente social. Diário Oficial da União: Seção 1, Brasília, D.F, p. 3, 27 ago. 2010.

BRASIL. Lei no 13.467, de 13 de julho de 2017. Altera a Consolidação das Leis do Trabalho 
(CLT), aprovada pelo Decreto-Lei no 5.452, de 1 o de maio de 1943, e as Leis nos 6.019, de 3 de janeiro de 1974, 8.036, de 11 de maio de 1990, e 8.212, de 24 de julho de 1991, a fim de adequar a legislação às novas relações de trabalho. Diário Oficial da União: Seção 1, Brasília, D.F., 14 jul. 2017.

BRASIL. Ministério do Desenvolvimento Social e Combate à Fome. Norma operacional básica de recursos humanos NOB/RH-SUAS. Brasília, 2006.

CARDOSO, Isabel Cristina da Costa et al. A especificidade do curso noturno: as dimensões pedagógicas e cultural na revisão curricular. Em Pauta, Rio de Janeiro, n. 1, 1993.

CFESS - CONSELHO FEDERAL DE SERVIÇO SOCIAL (org.). Assistentes sociais no Brasil: elementos para o estudo do perfil profissional. Brasília: CFESS, 2005.

CFESS - CONSELHO FEDERAL DE SERVIÇO SOCIAL. CFESS manifesta. Brasília: CFESS, 2017. Edição especial: A contrarreforma trabalhista. Disponível em: http://www.cfess.org.br/arquivos/2017-CfessManifesta- ContrarreformaTrabalhista.pdf. Acesso em: 25 out. 2018.

CFESS - CONSELHO FEDERAL DE SERVIÇO SOCIAL. Grupo de Estudos sobre Serviço Social na Educação. Subsídios para o debate sobre serviço social na educação. Brasília: CFESS, 2011. Disponível em: http://cfess.org.br/arquivos/subsidios-servico-social-na-educacao.pdf. Acesso em: 17 out. 2018.

CFESS - CONSELHO FEDERAL DE SERVIÇO SOCIAL. Resolução CFESS n. 383/99 de 29/03/1999. Caracteriza o assistente social como profissional da saúde. Brasília, DF: CFESS, 1999 Disponível em: www.cfess.org.br. Acesso em: 17 out. 2018.

CFESS - CONSELHO FEDERAL DE SERVIÇO SOCIAL. Resolução CFESS n‥ 273/1993, de 13 março de 1993. Institui o Código de Ética Profissional do/a Assistente Social e dá outras providências. Diário Oficial da União: Seção I, Brasília, D.F, p. 4004 a 4007, 30 mar. 1993. Disponível em: http://www.cfess.org.br/arquivos/CEP_CFESS-SITE.pdf. Acesso em: 12 out. 2018.

CONSELHO NACIONAL DE SAÚDE. Resolução no 218/1997. Reconhece o assistente social e outros como profissionais de saúde. Brasília, DF: CNS, 1997. Disponível em: www.conselho.saude.gov.br. Acesso em: 17 out. 2018.

DELGADO,Leila Baumgratz. Espaço sócio-ocupacional do assistente social: seu arcabouço jurídico-político. Serviço Social e Sociedade, São Paulo, n. 113, p. 131-151, jan./mar. 2013.

FECEA - FACULDADE ESTADUAL DE CIÊNCIA ECONÔMICAS DE APUCARANA. Proposta de readequação da matriz curricular do curso de Serviço Social. Apucarana: FECEA, 2009.

GOHN, Maria da Gloria. O protagonismo da sociedade civil: movimentos sociais, ONGs e redes solidárias. 2.ed. São Paulo: Cortez, 2008. v. 123.

IAMAMOTO, Marilda Villela. Os espaços sócio-ocupacionais do assistente social. In: SERVIÇO SOCIAL: direitos sociais e competências profissionais. Brasília: CFESS/ABEPSS, 2009. 
IAMAMOTO, Marilda Villela; CARVALHO, Raul de. Relações sociais e serviço social no Brasil. 17. ed. São Paulo: Cortez, 2005.

IPARDES - INSTITUTO PARANAENSE DE DESENVOLVIMENTO ECONÔMICO E SOCIAL. Diagnóstico socioeconômico do território Vale do Ivaí. Curitiba: IPARDES, 2007.

PARANÁ. Decreto-lei no 8.128, de 26 de out. de 2017. Renova o reconhecimento, pelo prazo de 04 (quatro) anos, a partir de 24 de março de 2016 até 23 de março de 2020, do Curso de Graduação em Serviço Social - Bacharelado. Diário Oficial [do] Estado do Paraná, Curitiba, PR, 27 out. 2017, no 10.057.

PORTES, Lorena Ferreira. Os fundamentos ideo-políticos da direção social que orienta a formação profissional em Serviço Social no Brasil: a apreensão de assistentes sociais docentes que atuam em escolas paranaenses. 2016. 368 f. Tese (Doutorado em Serviço Social e Política Social) - Universidade Estadual de Londrina, Londrina, 2016.

RAICHELIS, Raquel. Intervenção profissional do assistente social e as condições de trabalho no Suas. Serviço Social e Sociedade, São Paulo, n. 104, p. 750-772, out/dez. 2010.

SILVA, A. C. B. Das diretrizes curriculares à construção dos projetos pedagógicos em cada instituição. Cadernos ABESS, São Paulo, n. 8, p. 19-25, 1998.

UEL - UNIVERSIDADE ESTADUAL DE LONDRINA. Portal do egresso. Londrina: UEL, [2018]. Disponível em: http://www.uel.br/proplan/egresso/portal/. Acesso em: 4 nov. 2018.

UNESPAR - UNIVERSIDADE ESTADUAL DO PARANÁ. Apresentação geral da instituição. Paranavaí: UNESPAR, [2018]. Disponível em:

http://www.unespar.edu.br/a_unespar/introducao. Acesso em: 20 jul. 2018.

UNESPAR - UNIVERSIDADE ESTADUAL DO PARANÁ. O curso de Serviço Social. Paranavaí: UNESPAR, [2018]. Disponível em: http://www.fecea.br/humanas/mostrar_curso.php?id=6. Acesso em: 20 jul. 2018.

UNESPAR - UNIVERSIDADE ESTADUAL DO PARANÁ. Resolução n. 09/2015. Aprova a adesão da Unespar ao Sistema de Seleção Unificada (SiSU) e a distribuição de vagas nos Cursos de Graduação da Unespar para o SiSU e para o Processo Seletivo Próprio (Vestibular). Paranavaí: Unespar, 2015. Disponível em: http://www.unespar.edu.br/a_reitoria/atosoficiais/cepe/resolucoes/2015/resolucao_009_2015_cepe.pdf. Acesso em: 4 nov. 2018. 